\title{
The church organist's rappers: Redefining roles and strategies in music education
}

\author{
RVANAS ANDJ KRUGER ${ }^{2}$
}

\begin{abstract}
Arts and culture teachers often are ill-equipped to meet the requirements of school music programmes. They labour especially to accommodate the diverse musical preferences of learners. This discussion accordingly describes the implementation of a once-off rap programme at an inner-city secondary school in Pretoria. It shows the programme evolving fitfully into a remarkably effective synergy between a teacher (trained as a church organist), the formal schooling system, school learners as well as community musicians. However, this synergy was dependent on the teacher relinquishing her cultural and musical preferences in favour of a popular music programme linked to the social experiences of learners. The successful unfolding of this programme demanded that the teacher surrender the conventional status of omniscient, authoritative educator in accordance with the principles of learner-centered approaches. The role of the teacher consequently became that of project coordinator and facilitator, while the needs, goals and actions of learners were central to, and motivated experiential and reflective group learning. Learners applied theoretical knowledge in musical creation and performance, continuously assessed their progress, and redefined their objectives as required. The consequent development by them of a combination of communicative, cognitive, emotional and social skills reveals the value in music education of oral processes of learning, as well as the role of community musicians. It also underscores the value of the school as formal setting of social interaction and education, as well as the indispensable if redefined - role of the educator.
\end{abstract}

Keywords. Action learning, creative arts, music education, learner-centered education, rap

This discussion emanates from a rap music programme implemented at an inner city school in Pretoria in 2011 (see Van As, 2012). The experiences of staff and learners at this school are typical of such educational settings (see Au, 2005; Frierson-Campbell, 2006; Robinson,

1. Rosa van As is a church organist and music educator. She also teaches mathematics at a secondary school in Pretoria. She researched the topic as part of her MMus degree at North-West University, Potchefstroom Campus in the niche entity - Musical Arts in South Africa: Resources and Applications.rvanas@dinamix.co.za

2. Jaco Kruger teaches musicology in the School of Music, North-West University, Potchefstroom Campus (Niche Entity - Musical Arts in South Africa: Resources and Applications). 10193405@nwu.ac.za 
2006). The school's culturally diverse surroundings are manifested in the composition of both its learner and educator bodies. This diversity is attendant upon urban spatial change which is marked by the disintegration of original business hubs, and the inflow of unemployed and homeless people from peri-urban and rural areas, as well as neighbouring countries. Accordingly, a significant number of learners at the school under discussion live in conditions characterised by material deprivation, fractured families, violence and substance abuse. Needless to say, providing relevant, effective education to them is replete with challenges whose resolution may require innovative thinking.

\section{The challenges of school music programmes}

The colonial legacy in South African formal music education is that of music literacy and the study of Western 'art' music. The well-known Human Sciences Research Council music education report of 1993 accordingly identified a "crisis of relevance" related to a "Western monogenic music education programme" (Smit \& Hauptfleisch, 1993:25-28). Although this legacy has since evolved autonomously into local operatic, orchestral and choral singing practices (see e.g. operaafrica.co.za, buskaid.org.za, thutong.doe.gov.za/schoolenrichment), it continues to be redundant in many local communities: School choristers in Free State Province identified their music of choice as gospel and "Sotho music" (Dzorkpey, 2010), ${ }^{3}$ while a survey conducted by Van As (2012) amongst eighty grade 8 and 9 learners at the inner city school under discussion revealed a preference for local forms of house music $(37 \%$ of the sample) and rap (34\%). That rap is a form of expression of knowledge and meaning for these learners is evident in a remark by one of them that

\section{[I]t is much more than dance - it is a culture [in which] you can talk about the food you eat, about money, about the person you want to marry, about everything that happens in your life. You live by it. That is what people do who believe in it. They do everything according to it. ${ }^{4}$}

The current Curriculum and Assessment Policy Statement (CAPS) for the Creative Arts (senior phase, grades 7-9) is a response to the constitutional mandate to "improve the quality of life of all citizens and free the potential of each person" (CAPS for the Creative Arts, 2011:3). This it aims to achieve, inter alia, by including the study and performance of "folksongs (indigenous songs, cultural songs)" and popular music.

While the curriculum therefore has a firm, socially-engaged philosophical foundation, its implementation remains mired in a "crisis of provision" (see Smit \& Hauptfleisch, 1993:4970). Tertiary training programmes in music education are challenged by the large number of diverse music cultures in South Africa. In addition, they significantly still reflect the colonial

3 In contrast, the South African Schools Choral Eistedfodd, a national choir competition for secondary schools administered by the Department of Education, includes a category for Western opera ill-suited to the abilities and musical experiences of most choirs (see Dzorkpey, 2010).

4 Compare Juslin, 2005:85. American hip-hop artist KRS-One similarly remarks that "Hip-hop is something you live, rap is something you do." (Adaso, 2011.) All statements by learners were made during the running of the rap programme at their school during 2011.

5 Prior to the 1993 Human Sciences Research Council report, a process already had been initiated to source local African musical cultures in music education (see Lucia, 1986). The Talking Drum, an African music education resource journal, was launched in 1992, and still provides music teachers with valuable support. 
legacy of classical 'high art'. While tertiary jazz programmes have gained a permanent foothold, the same cannot be said for popular music programmes which are implemented poorly. Arts teachers therefore often find themselves at a loss when confronted with the CAPS for the Creative Arts. Not only do they not always share the musical preferences of learners, but they also are expected to offer tuition in dance, drama and the visual arts. Creative arts education therefore often is offered piecemeal by teachers ill-equipped for their task. So, for example, instruction in music in the arts and culture programme for grades 8 and 9 at the school concerned was restricted to a non-practical overview of musical instruments. There was no specialist music teacher at the school, and musical performance took place irregularly and extra-murally under the direction of volunteers.

Although employed as a mathematics teacher at the school, Van As is a qualified music educator, and had been conductor of the school choir for several years. She founded a music and dance festival in 2010 to showcase cultural diversity among learners. In keeping with the popular notion of timeless ethnic identity, learners and community members presented older, 'traditional' musical forms at the first festival. An unexpected request by a learner for the inclusion at the festival of a rap performance sensitised Van As to the biased and maladaptive nature of notions of static identity, and acted as stimulus for the implementation of a rap programme at the school.

\section{Implementing a rap programme: the challenge of method}

Although a significant percentage of learners at the school expressed a preference for house music (mainly a dance form), the verbal nature of rap seemed to offer Van As, as cultural 'outsider', more rewarding access to the experiences and worldviews of learners. The twomonth programme accordingly set out to offer learners an opportunity to develop skills in rap composition and performance, and in so doing to contribute to the development of their personal and social well-being.

Implementing these objectives clearly called for methodological circumspection, given the statuses as well as musical skills and preferences of those involved: Van As and her learners were from different ethnic origins in a country still scarred by racial stereotyping; they also were distinguished in terms of age; although conductor of the school choir, the primary status of Van As as a mathematics teacher did not correlate with her proposed involvement in the rap programme ${ }^{6}$; furthermore, Van As is a church organist, and she finds the frequent explicit content of rap morally objectionable. As such, it was glaringly evident that any successful implementation of the programme would be dependent on Van As relinquishing her personal and cultural preferences ${ }^{7}$ as well as any insistence on the conventional status of omniscient, authoritative teacher in favour of receptiveness towards the use of popular music in education, as well as a reconceptualised role allocation in accordance with learner-centered approaches.

6 However, Van As had established prior rapport with her mathematics learners through musical activity. These learners internalised mathematical formulae and short descriptions of methods by performing them to existing melodies. This promoted learners' interest in mathematics and helped to accommodate diverse styles of learning (see Van As, 2009).

7 As this discussion shows, learners were aware that other adults also did not approve of the explicit nature of certain rap songs, and consequently avoided offensive lyrics in their school rap project. 
Any one or combination of the plethora of contemporary learner-centered methods arguably would have been suitable for the implementation of the rap programme. However, the particular circumstances and objectives of the programme aligned themselves particularly well with the action learning approach. ${ }^{8}$ This pioneering approach was developed in the 1940s by Reginald Revans in the field of business management (see Revans, 1980; 1984). In contrast to the popular notion that learning somehow precedes experience, Revans argues for the practical acquisition of knowledge within particular professional environments. Although mainly aimed at executive leadership training programmes, action learning applies to most contexts where learning is linked to specific outcomes. Revans's approach accordingly has been applied in music education by Regelski (1981, 1983, 1986), and it has, in dynamic mergers with other learner-centered approaches, resonated in the influential praxial musical philosophy of Elliott (1989; 1995; 2009), with its emphasis on music as meaningful interaction, as well as contemporary perspectives along the interface of formal and informal music education (see Schippers \& Bartleet, 2013).

Pared down to their bare essence, the principles of action learning selectively applied and adapted in the rap programme were the following (see especially Regelski, 1983b:48): The role of the educator was that of project coordinator and facilitator of teaching-learning in cooperation with community experts (in this case, professional local rappers); the needs, goals and actions of learners were central to, and motivated learning; group learning was a core activity; learning was experiential and reflective: Learners applied theoretical knowledge in musical creation and performance, continuously assessed their progress, and redefined their objectives as required.

The objective of this essay is not to provide any in-depth review or critique of the extensive writings on action learning, but a broad discussion of the application in the rap programme of the tenets of action learning as set out above. In particular, it describes how these tenets helped to redefine the conventional relationship between educator and learner, and in so doing enabled the production of a successful rap concert. In this process it illuminates aspects of the relationship between school and community, as well as formal and informal teaching. As such it also aims to contribute towards the "growing awareness and recognition of the connections between community musicians, music making, and education" and the development of alternative models of music teaching-learning "in order to widen the framework dictated by the history and structure of formal music education in terms of content, methodology and practice" (Schippers \& Bartleet, 2013:457).

\section{Applying action learning principles}

The programme was structured into the following operational phrases: Learners from grades 8 and 9 responded to an invitation by $\mathrm{Van}$ As to join the programme. They in turn recruited other group members. Groups then met with Van As to identify their objectives and strategies. Following this, the groups created their rap songs under the direction of Van As, and with the assistance of local professional rappers. This process evolved over a period of several weeks and culminated in a school concert that showcased the group's compositions and acquired performance skills. 


\section{The role of the educator and professional experts}

The first meeting between educator and learner was marked by surprises and doubt. However, this meeting, as well as the next few, were to be seminal in the unfolding of the programme.

The meeting was attended by a few learners only, none of whom had rapped before. They subsequently indicated that they were excited, but nervous and shy. Their anxiety was fuelled by Van As's announcement that she did not merely intend to facilitate a platform at school for rap performance, but also wanted to play an active role in the process leading to the planned concert. They distrusted her unexpected interest in their music, and one learner thought that her plans were offered as a joke. Others politely expressed their skepticism in questions and statements like "Ma'm, are you sure you want to learn more about rap?" and "You know, this is not holy ground!" They knew that some adults disapproved of the explicit content of some rap styles, and therefore diplomatically suggested that Van As might want to implement her plans elsewhere with gospel rappers. However, Van As managed to convince them of her sincerity after further negotiation, and the group somewhat reluctantly but courteously agreed to meet during school breaks to implement the programme. These meetings soon attracted the curiosity of other learners, and the group finally expanded to nineteen members.

The fact that Van As managed to convince learners of the integrity of her intentions does not mean that she performed her role with any modicum of ease. To the contrary, she experienced her engagement with rap as a culture shock, and she was acutely aware during the entire programme that her gender, ethnic affiliation, age and moral values often were in conflict with the conventions of rap culture.

The initial phase of the programme was most challenging since Van As was relatively unfamiliar with rap practices. Her ignorance was met with disbelief and even boredom, and she had to field questions like "Ma'm, do you really not know what the meaning of swag [confidence] is?" In addition, learners' progress was slower than anticipated, while the programme had to be completed within a constricting time span. Also, the programme met with apathy from the school's management as well as staff. An event at the school to market the concert was disrupted by jeering, ill-disciplined non-rappers, and this impacted severely on the morale of all involved in the programme. The description of the innovative educator getting worse before getting better (Green, 2008:54) accordingly correlated fittingly with constant feelings of discouragement and alienation, and Van As's immediate, subconscious response was to take refuge behind her video camera. However, the selective implementation of the principles of action learning eventually became the only effective response to these conditions and feelings. Shaking off the fear of losing control over the programme required the calculated trusting of learners to achieve objectives, according a primary pedagogical role them and co-opting professional rappers into the teaching-learning process (see Revans, 1981:260).

Nudging learners to the pedagogical centre, while stepping back, was easier said than done, and ingrained teacher-centered habits asserted themselves powerfully during the first phase. By way of introduction, Van As offered learners a formal overview of rap genres, styles of rhyme and rhythm, rap themes and language (see Krims, 2000). Not surprisingly, learners quickly became bored, but were too reticent to express any objections. The situation called for the immediate implementation of two strategies: Van As had to be true to herself by admitting ignorance about rap performance practice, and the role of learners in the teaching- 
learning process had to be reconceptualised (see Regelski, 1981:373). Consequently, learners played and discussed their favourite rap songs at the meeting that followed. Some learners with practical rap experience even demonstrated their skills. Discussion expanded to the worlds of rapping by means of an analysis of the term swag (confidence, self-assertion). As we will show, this discussion established a clear link between poverty and the materialistic values that characterise certain forms of rap. The conversation was lively, spontaneous and often changed direction. Learners were so enthusiastic at the end of this session that they wanted to meet again later that day.

This redefined approach to teaching-learning became increasingly fruitful: Learners started sharing their knowledge with increasing freedom, and the relationship between them and Van As gradually changed, resulting in constructive, often unforeseen consequences. One of Van As's first displays of her newly-acquired knowledge was the spontaneous incorporation of rap vocabulary into her speech patterns. ${ }^{9}$ This was a clear, practical sign of her commitment to the programme, and it helped to cement her bond with her learners.

While Van As in this way steadily accumulated knowledge of the rap genre, her lack of practical skills, as well as the subordination of the extra-mural rap programme to the school's formal academic programme, ${ }^{10}$ necessitated a process of accelerated creativity and skills acquisition. This was achieved by co-opting local professional rappers into the programme, an indispensable reversal of Revans's strategy to involve 'non-experts' in problem-solving situations (see Revans, 1980:30). ${ }^{11}$ These rappers had been identified by learners in the programme. They had completed their education at the school, and were now building careers as professional artists. Rapper Bugzito was particularly excited, remarking that he never would have dreamed a rap programme would one day be implemented at the school. Accordingly, he and fellow rappers were exceedingly committed to their task. ${ }^{12}$ They faithfully attended all meetings during the week as well as over weekends, and patiently provided learners with practical advice. As we show below, the social status and skills of these rappers offered them authority as facilitators, and thus fostered the creative process.

The redefinition of Van As's role, as well as the involvement of local rappers, however, did not negate her function as coordinator and facilitator. This role required the effective structuring of groups, offering advice and encouragement, ensuring progressive learning, selfassessment and the on-going reformulation of objectives, and generally creating conditions conducive to effective learning (see Pedler et al., 2005; Regelski, 1981; Revans, 1980).

$9 \quad$ Especially “spit your chorus!"

10 The programme had to be completed within two months so as not to interfere with the school's academic schedule. Furthermore, meetings were restricted to school breaks, and otherwise took place after hours and even over weekends.

11 Revans argues that experts tend to overlook the obvious, and apply proven solutions rather than assess new situations in their own terms. This approach also may inhibit participants from developing their own solutions and problem-solving skills.

12 Some of them had to walk long distances to get to the school. In addition, they struggled with their own studies, and often were so hungry that they expressed gratitude for a humble sandwich when arriving at meetings. During a conversation about possible prizes for participants, one remarked, "A meal voucher sounds wonderful to me, because all I can think of now is food." 


\section{Addressing the experiences and needs of learners}

In keeping with the tenets of learner-centered methods, the experiences and needs of learners is a fundamental principle of action learning. Objectives are not related to imaginary situations but to actual, shared concerns which become the practical motivation for learning (Revans, 1980:53). Regular remarks by learners not only underscored the need for school music programmes, but specifically also those that would enable the musical expression of their social experiences, worldviews and emotional conditions, function as sites of social interaction, and help to open up professional possibilities.

Learners accordingly emphasised the importance of expressing themselves in a musical form of their choosing, remarking "We would not be as enthusiastic if [another type] of music was prescribed by the teacher. We are glad that we can do something to which all young people can relate, something we all enjoy." As the remark by rapper Bugzito indicates, extensive popular music programmes are rarely offered at school. Learners expressed their gratitude at being able to join the rap programme, and remarked that it empowered them.

Contrary to the hedonistic stereotyping of rap, learners indicated that rap performance is a suitable medium for serious self-reflection: "[Rap allows us to] talk about our present, our past and our future, about our dreams and the hope that lives inside us, about our experiences at school, about perseverance, and about life as an adventure." The group unanimously formulated the theme My story, my vision, and lines from their songs accordingly stated "Look up, look: the future has arrived" (Jai Tea: Good fella), "Now let's stand together and tell all the haters we have our backs right" (Toxic: Rockin' like mine), "Make your mum proud, 'coz we are the world's future" (Lesley: Youth anthem), "I'm up the sky, higher than a mountain" (Luyanda: Success) and "With God I stay linked" (Toxic: Keep on going). ${ }^{13}$

Learner Denise was convinced that she would gain control over her turbulent emotions if she could work through them in rehearsal, and declare them openly in performance. Only her close friends fully understood the verbal metaphors that expressed her feelings regarding the divorce of her parents, as well as other discouraging life experiences. She was learning to adjust to the fragmentation of her family, and compared this process to buying a new car, since it was the beginning of a new phase in her life:

I'm a swagga on a zillion. ${ }^{14}$

Luiy $V$ down.

Like a luiy $V$ camillion. ${ }^{15}$

I was so stree'like I live in a building.

No chandeliers, I got guns hanging off the ceiling. ${ }^{16}$

Brand new car.

Stanley (1992:xxii) accordingly notes of early forms of American rap that they were "generally exuberant and upbeat" and "devoted more to uplift than to anger." Accordingly, rappers in the programme discussed here generally viewed their performance a means to educate and build community solidarity.

"Zillion" quantifies Denise's love and admiration for her mother who is her role model.

"Camillion" refers to a chameleon. The ability of the animal to change colour is a metaphor of Denise's need to adapt to changing circumstances.

A metaphor for the trauma accompanying the divorce. 


\section{I divorced a cop. ${ }^{17}$}

Say brand new car, brand new car.

\section{(From Brand new car)}

Denise was the only female rapper in the programme, and for many girls at the school she eventually became iconic of how their own personal and gender struggles could be surmounted.

While the rap programme therefore evolved as a means of intimate personal expression for certain individuals, it provided an opportunity for all to display social competence and selfassertion, and to impress others (especially the opposite gender) in the mastery of their mode of expression. Toxic, in his song Keep on going, accordingly remarked: "I got ma raps/ Got ma rhymes/ Got ma lyrics just in line/ Got ma haters left behind", while Jai Tea (Good fella) boasted: "The one and only undisputed, the good fella/ The one and only Casanova, with ladies/ The one and only Land Rover, with MCs". ${ }^{18}$ Swagga in turn remarked after the concert that his performance gave him confidence, and infused him with the emotional energy needed to meet challenges. Telly Gang, a group of academic underperformers, identified in their participation in the concert an opportunity to present themselves as competent learners, and their song accordingly stated: "I'm in the school of success/ the school of talent and challenge/ where champions are made."

While these notions of success were expressed in general terms, they took on specific, professional relevance for several learners who saw the programme as a professional training opportunity. Jai Tea accordingly stated in his song Good Fella:

I'm not imaginary.

I'm a legendary rapper in the making.

I'm extraordinary.

I'm a bistoric era.

A legend forever.

One day I'm gonna be on the library shelves.

Rapping is my best profession.

Living in a culture of poverty, successful local and international rappers are role models to these young inner city rappers, and learner Kamogelo remarked that he specifically strives to emulate the success of famous American rap artists. In predictable contrast with their socially constructive values, these young rappers also expressed a strongly materialistic worldview in their conversations and songs. In response to the question by Van As, "How does a person with swag act?", learners remarked that people with swag have "style and self-confidence", based on what they possess. Money is especially important to rappers since most of them live in squatter camps. People want to be friends with a successful rapper "in the hope of getting something out of him. This makes him feel important. The more money someone owns, the more girlfriends he has." (Van As, 2012:57-58.) Learner Skhumbuzo accordingly remarked

17 Denise's father is a traffic officer.

18 MC: Master of ceremonies, a reference to expert rapping. The Land Rover is a favourite vehicle of local political leaders and successful businessmen, and consequently symbolises power and wealth. 
in Youth anthem: "I want to be the bravest man like Mandela/ Getting all my distinctions like Mugabe/ Getting my cash/ Firing like Obama."

\section{Group learning and support}

Central to Revans's concept of action learning is not the external expert, but those in the workplace who reflect on themselves in groups or so-called action learning sets (Revans, 1980). These groups meet on a regular basis for discussion, cooperation and reflection. They ideally function consensually and take their own decisions in an environment of honesty and acceptance (see Dilworth, 1998:36; Regelski, 1981:296). Achieving these aims in the rap programme was promoted by the circle formation. Facing each other markedly promoted cooperation and feelings of coherence among all participants. This was especially the case following the disrupted marketing meeting. Responding to verbal abuse by non-rappers (e.g. "Any person can rap - it takes no special skill"), one of the learners in the programme remarked laconically: "You have to deal with [take] things like this."

Such shared experiences and sentiments were key to the successful implementation of the rap programme. The initial euphoria induced by visions of stardom was soon tempered by the discovery that composition and performance requires hard work and perseverance. However, learners garnered strength when they realised that all faced the same problems, and they soon developed the skill of encouragement and actual assistance. Support in some cases was extensive, as is evident in our discussion of the relationship between learners Swagga and Skhumbuzo (see "Creating lyrics"). Remarks by learners about the advantages of group formation pointed to intensified relationships and an awareness of interdependence and mutual responsibilities. These qualities engendered trust and feelings of security, and Jay Weezy noted that his group made him feel free and excited. Learners generally indicated that interaction improved their sense of self-worth and helped to develop their personalities.

Relationships were also cemented through support and the sharing of knowledge by learners not participating in the programme. Denise's friends realised she would benefit from expressing her emotions about her domestic life in her performance, and they encouraged her to participate in the concert. Jai Tea's rehearsals were even supported by his non-participating friends. They also joined his post-concert reflection session.

Members of the rap programme obviously were characterised by their status as learners at the same school, their musical preferences and shared programme objectives. Jay Weezy accordingly remarked: "I can be in contact with others due to our shared interest in rap." More specifically, however, individual groups tended to form on the basis of friendship. ${ }^{19}$ Learners joined groups who shared their specific worldviews and cooperated amicably. Several groups furthermore were molded according to shared academic performance. One such group comprised learners who were repeating their grade while another, the Crazy Saints, consisted of four achievers who remarked:

I've got dreams and ambitions of Julius Caesar.

I can be cold as ice but boiling like a geyser.

Although learners were required to work in groups, some asked to present an individual performance, so that six groups and three soloists eventually took part in the concert. 
You ain't got nothing on me, I'm a dream reacher.

On being light weight title: don't test me, I'll beat ya.

(Extract from Teenagers)

The group Fire Line was an exception in that they were composed of casual acquaintances. The conversation that led to their formation was short and to the point:

"Can you rap?"

"Yes, but preferably in my mother tongue!"

"[OK] let us form a group and take part in the concert!"

"Yes, we can practise every break."

"Ofentse can create us a beat with Fruity Loops" and OT can provide sound effects with beat boxing." 21

However, not all attempts at group formation were so simple and successful. Approximately a quarter of those initially interested in the programme withdrew gradually. Some lacked commitment, while others found it too difficult to accommodate the pressure associated with performance. Some groups therefore either disbanded altogether or lost members to other groups, a process that continued until shortly before the concert.

\section{Teaching-learning is reflective and experiential}

Reflection is cardinal in action learning, since learning and behavioural change is argued to take place most effectively when learners continuously conceptualise, test and defend their positions, and experience the outcomes of their own proposals and actions (Revans, 1980). Swag Stars fittingly asked themselves: "What must we do to stage a successful performance? Should such a performance include dance movements? If so, where can we get dance tuition from?" One of the outcomes of this reflection was that the group successfully incorporated new dance movements in their concert presentation.

The entire group formulated and pursued the following main performance objectives: 1) Individuals initially had to create their own rap lyrics. 2) These lyrics had to be adapted and integrated into a group composition. 3) Performers had to learn how to "flow with the beat" (fit lyrics to a metre). 4) Each group had to create a suitable pre-recorded instrumental accompaniment and learn to use sound equipment effectively. 5) All learners had to organise and participate in a stage performance at the end of the programme.

\section{Creating lyrics}

Professional rapper Bugzito advised learners to reflect constantly on relevant life issues so as "never to be without words." For learner Piet, this translated into stating "who we are, what

20 The implication is that a box of Fruity Loops (a cereal) can become a percussion instrument.

$21 \quad$ Vocal percussion. 
we dream about and what gives us courage to go on." While the choice of themes was therefore relatively self-evident, learners' lack of experience of composition and performance required special input from Van As and the professional rappers. So, for instance, Van As showed learners how to analyse their social experiences, and describe them in original and interesting ways by applying linguistic devices like adjectives, synonyms, internal rhyme (alliteration and assonance) and end rhyme. One meeting was dedicated to developing the skill of replacing commonplace expressions with new and attractive descriptions. Learners were asked to list five aspects of school life. Each aspect had to be qualified with a list of suitable references (e.g. school break: sit, eat, conversation, laugh, friends). Each of these references in turn had to be extended (e.g. soft green grass, cheese sandwich, lively chat). Learners now had to construct two sentences around each reference. They then had to practise chanting these sentences to a particular metre, on a selected pitch level and at a suitable tempo. This exercise not only developed the essential skill of verbal formulation and "flowing with the beat" (see the discussion that follows), but also established the importance of an expressive delivery.

This skills development drill was an important opportunity for Van As to regain her confidence as educator. Her additional experience as qualified language teacher had equipped her with the knowledge and authority necessary to play a leading role in this phase of the training process, one she performed with ease and spontaneity. This is not to identify this role as exclusive. Swagga dedicated himself to helping his friend Skhumbuzo (who belonged to a different group) to write lyrics and set them to a metre. Skhumbuzo was asked to reflect on his theme and write down his ideas. These ideas were then transformed into lines, as if writing a poem. Swagga then played an accompaniment and asked Skhumbuzo to read the lines while superimposing them on the metre. When Skhumbuzo stumbled, Swagga demonstrated how he should fit the words and flow with the beat. Skhumbuzo persevered until he was successful. He had learnt that his speech tempo had to correlate with the tempo of the beat. Although his rhyme tended to stay somewhat forced, he had reached his personal objective, and his group (Swag Stars) ultimately would rap: "This is SA/ I never look back/ I hate history ${ }^{22}$ This is my say!"

The joint group initially decided that they should rap in English. A request by a learner for the inclusion of "perhaps a few words in your own [African] language to make you feel at ease" was rejected "because someone can insult your mother in another language without you being aware of it." It was therefore confirmed that songs for the concert should only be in English, and that foul language or references to violence, sex, pregnancy, drugs or other inappropriate topics were forbidden. Van As's trust in her learners was starting to pay off since they were tempering their descriptions of their experiences, and apologised when they used the occasional explicit expression.

\section{"Flowing with the beat"}

According to professional rapper Tony, "flowing with the beat" involves the integration of lyrics, metre and tempo that gives a song its unique expressive power: "It is not what you say, 
but the way you say it." Green (2008:60) in turn describes flow specifically as the capability to sing each note at a point precisely on or around a beat (also see Adams, 2009).

For most participants in the programme, achieving flow was the most demanding creative challenge. This is not surprising as it involves integrating lyrics, metre, rhythm, tempo, dynamics and form (song structure). Learners were advised by programme facilitators to first listen to many styles of rap, structures of flow and rhyme schemes before selecting a metre. They then demonstrated how accents may occur on weak as well as strong beats, and how to "relax while talking over the beat." They also explained that a rapper has to develop the ability to think and take decisions in a split second. This is only possible when performers maintain the metre when introducing variation in the lyrics. Such variation is one of the basic features of rap, and once it is mastered, perfect flow will be achieved. In a group context, flow is also dependent on good coordination between members.

Learners were encouraged and guided by the programme facilitators to experiment freely and continually reflect on their creative efforts (see Dilworth, 1998:36; Regelski, 1983b:47). However, good advice by the professional rappers did not invalidate the value learners attached to their own tried and tested methods. For example, little consensus could be reached about the ideal way to integrate lyrics and metre. Some learners, like Toxic, argued that it is best to first find an accompaniment, to determine the metre, rhythm and tempo, and then to fit the lyrics: "I listen to the beats while I write the lyrics because then I know how the beat flows." Samkele in turn argued that it is not possible for one person to teach another how to flow. Several learners pointed to the importance of listening to the beat while writing lyrics. Swagga remarked that he is influenced by the way that well-known rapper Lill Wayne's performances flow.

\section{Showcasing the songs}

The group's creative efforts were showcased at a school concert at the conclusion of the programme. Learners were guided in marketing the concert by word of mouth, posters and pamphlets. Learners who were graffiti artists, and did not participate in the programme, designed the posters.

The concert mobilised learners and staff not directly involved in the programme, and created a wider sense of ownership and participation in culture change at the school. The school's cultural committee took responsibility for organising masters of ceremony (MCs) for the concert. These MCs included learners from senior grades, and they helped groups during their final rehearsals, prepared the school hall for the concert, and sold tickets. The school's disciplinary committee also became involved. They roped off the front of the stage, and appointed staff who were responsible for maintaining order during the concert. ${ }^{23}$ All those who offered assistance during the concert were asked to dress in rap fashion, and this helped to visualise support and shared experience.

Final rehearsals quickly revealed that most performances were not yet acceptable: Not all participants knew their lyrics, accompaniments had not yet been prepared adequately, the membership of some groups had changed, while there were also technical problems with recorded accompaniments. Learners discovered that final preparation was very demanding 
and time-consuming. Rehearsals in front of friends helped the young rappers to overcome their initial nervousness, acquire experience, rectify mistakes and round off their song. Groups also influenced and inspired each other during these rehearsals. These strategies had prepared the groups well for their concert.

The concert stood in stark contrast to the humble, doubt-ridden start of the programme. Although not all performances were equally successful, the concert was a real achievement. The audience's enthusiastic response boosted the confidence of the young performers. The performance by Jai Tea, the most accomplished rapper, was met with such enthusiastic response that an experienced, older MC expressed his regret at not also participating in the concert. Comments from members of the audience included "I enjoyed my friend's rapping", "The concert was off the hook!" and "The rappers flowed with the beat like professionals."

Staff who attended the concert also valued the rap performances, and the principal expressed surprise at seeing successful performers not otherwise noted for excellence in any field related to formal schooling. To him, the concert showed the need to accommodate as many learners as possible in a wider diversity of academic as well as extra-curricular programmes.

\section{"A new chorus": assessing the programme}

The implementation of the rap programme has shown that the application and adaptation of specific principles of action learning in an extra-mural school teaching-learning programme may offer meaningful education. The efficacy of the programme was attendant upon the redefinition of the relationship between educator and learner, its relevance to the social experiences of learners, as well as the incorporation of dedicated professional artists.

The programme equipped learners with a combination of communicative, cognitive, emotional and social skills. In terms of their cognitive skills, their acquired ability for artistic as well as interpersonal analysis and reflection was of particular importance. Learners overcame the core creative and performance challenges of rap, namely creating lyrics (thus developing their literary skills) and learning to flow with the beat, i.e. to articulate their words clearly and fluently in relation to a fitting metre and rhythmical patterns. This achievement was possible because they had learnt to listen critically to, and evaluate performances.

Learners marketed and organised their own concert, and then performed successfully to an audience in accordance with the conventions of rap. In this process they discovered first-hand some of the basic characteristics of all successful artists, namely that they are imaginative, express authentic experiences and emotions, and strive for excellence but not necessarily perfection.

In terms of social interaction, learners developed an ability to solve problems by sharing knowledge, listening to and evaluating the views of others, and making decisions that benefitted the group (see Ley, 2004:40). They also learned the value of acceptance, encouragement and patience.

The personal rewards of the programme for learners were particularly moving. Denise explained how rap performance enabled her to overcome the hurt of her parents' divorce, while Swagga, who harboured deeply negative sentiments about his life, remarked that musical expression encouraged him, and directed his energies towards the kind of future that would make his mother proud of him. The song of his group (Swag Stars) was accordingly 
entitled Youth anthem, and its chorus noted: "Dreams come true/ Lies we leave/ Future we shape."

Empire similarly indicated that he had experienced a "breakdown" before joining the programme: "You know, m'am, things are bad at home. Thanks for the opportunity [to perform]. I worked hard." Karabo, a quiet, reticent young man who was experiencing serious stumbling blocks in his schooling, in turn often consulted personally with Van As about his group (Telly Gang), and ultimately presented himself with confidence on stage. His remarkable personality change was mirrored in the increasing freedom and spontaneity that another learner, Ofentse, had developed on stage. He was fond of catching Van As's eye, and once remarked: "M'am, you will really like our new chorus." This remark resonated beyond its immediate utterance as a succinct summary of the life-changing process that several members of the programme had experienced. This process extended to Van As who had changed her attitude about the value of popular music in education, established extant friendships with professional rappers, and experienced increased bonding with her mathematics classes, with improved academic results.

\section{Conclusion}

South African music education has come a long way since the era of racially segregated schools, enforced knowledge systems and concomitant claims to cultural superiority, as well as a conception of the educator as authoritative dispenser of all true knowledge.

Elliot (1989:17) notes that, in order to accommodate greater musical ideas, processes and problems, music education should be liberal enough to go further than certain cultural preferences. This implies an accurate understanding of what music is and does, and the effective educational application of our consequent knowledge. The success of the rap programme was dependent on a strategy that generated knowledge for meaningful living. The production of musical sound must be mastered, but such sound has no objective value, and people do not transform their social environment through autonomous musical energy: They do so through human energy which is organised and released through music making. Local forms of rap may be regarded as vehicles of artistic expression that link with ancient African musical practices, ${ }^{24}$ and which address contemporary experiences by tying their performers into the mass media and other global networks of value and meaning. History is not only a narrative of ruling power and mass movements, but also of humble individuals and small groups acting cooperatively and innovatively under pressing conditions.

The rap programme unfolded as the remarkably effective synergy between a classically trained church organist, the formal schooling system, rappers from an inner city school, and community musicians. This synergy shows the value in music education of processes of learning in oral cultures, as well as the role of community musicians. At the same time, it underscores the value of the school as formal setting of social interaction and education, as well as the indispensable - if redefined - role of the educator.

The relative success of the rap programme should not blind us to the challenges of music education. While curricula may envisage a flourishing, compassionate society in their 
outcomes, they by definition do not offer effective practical strategies for providing meaningful education to populations marked by cultural diversity and various forms of conflict. Process-oriented pedagogy is by no means self-evident (see Schippers \& Bartleet, 2013: 469): Its final form is shaped by specific local conditions, and it may be realised only by heroic struggles.

While the rap programme arguably exceeded most of the outcomes of the CAPS for the Creative Arts (see below), it involved volunteer learners, and its efficacy in a general, diverse population of learners cannot be ensured. Also, while community facilitators played a crucial role, they too were volunteers, and their kind of involvement in formal educational programmes is fraught with challenges related to institutional appointment policies and labour laws. ${ }^{25}$

The rap programme, as a mode of extra-mural teaching-learning, linked closely with the outcomes of the CAPS for the Creative Arts (grades 7-9). It not only improved the quality of life of learners and realised their personal potential, but also met several of the specific outcomes of the CAPS music programme: It involved listening and performing, explored metre and rhythmic patterns, "told a story" by means of lyrics, and required vocal improvisation as well as mastery of the verse and refrain structure. However, there is one outcome of the CAPS music programme that was not achieved by the rap project, namely the requirement of musical literacy. There is little doubt that efforts towards developing musical literacy would have been counterproductive in implementing the programme. The emphasis in the CAPS on literacy arguably is a colonial heritage that links with the notion of high and folk art, of illiteracy as an ostensible form of underdevelopment. However, it must be understood that literacy is not a requirement in communities where effective forms of communication have historically been, and to some extent still are, oral. ${ }^{26} \mathrm{It}$ is our argument here that the successful implementation of music programmes in the CAPS is not necessarily dependent on musical literacy, and that a mainly aural method of teaching-learning may be more effective.

Finally, if we argue that the vision of innovative music education is to restore music making to its primordial status as a basic cultural resource, it is because we have come to learn anew that musical performance may, in the immortal words of John Blacking, create a "soundly organised humanity" (Blacking, 1976). Modern forms of labour and their accompanying worldviews often fracture the wide variety of individual skills that our distant ancestors once possessed, and thus remove musical ritual from our daily experiences. And so we often fail to utilise and even recognise the socially constructive potential of artistic production. An impersonal, alienating world requires us to re-establish once habitual face-to-face relationships. Our challenge is to show society why the creative arts should not flounder on the educational periphery. We can achieve this by flowing with the beat of our local communities without fear, and letting them experience their true selves. This has implications for the social well-being of our children, and, ultimately, the effective adaptation of our society.

This is particularly the case with older forms of African expressive culture, whose community practitioners typically do not possess the formal qualifications that the education system requires. 


\section{References}

Adams, K. 2009. On the metrical techniques of flow in rap music. Music theory online: $A$ journal of criticism, commentary, research and scholarship, 15(5). Oct. http://goo.g1/DjlzWD Date of access: 28 Apr. 2012.

Adaso, H. 2011. A brief history of hip-hop and rap. http://goo.gl/niZhlG Date of access: 2 Sept. 2011.

Au, W. 2005. Fresh out of school: Rap music's discursive battle for education. Journal of Negro education, 74(3): 210-220.

Blacking, J. 1976. How musical is man? London: Faber \& Faber.

Dilworth, R.L. 1998. Action learning in a nutshell. Performance Improvement Quarterly. 11(1):28-43.

Dzorkpey, T.K.A. 2010. Realising the objectives of the South African Schools Choral Eisteddfod. Unpublished PhD thesis. Potchefstroom: North-West University.

Elliott, D. 1989. Key concepts in multicultural music education. International Journal of Music Education, 13.

Elliott, D. 1995. Music matters: A new philosophy of music education. New York: Oxford University Press.

Elliott, D., ed. 2009 Praxial music education: Reflections and dialogues. New York: Oxford University Press.

Frierson-Campbell, C., ed. 2006. Teaching music in the urban classroom: a guide to survival, success, and reform. Oxford: Rowman \& Littlefield Education.

Green, L. 2008. Music, informal learning and the school: a new classroom pedagogy. Hampshire: Ashgate.

Juslin, P.N. 2005. From mimesis to catharsis: expression, perception, and induction of emotion in music. (In Miell, D., MacDonald, R. \& Hargreaves, D.J., eds.Musical communication. Oxford: Oxford University Press. p. 85-115).

Krims, A. 2000. Rap music and the poetics of identity: New perspectives in music bistory and criticism. Cambridge: Cambridge University Press.

Ley, B. 2004. Developing musical skills. (In Marks, A., ed. All together! Teaching music in groups. London: Royal Schools of Music. p. 35-45).

Lucia, C., ed. 1986. Proceedings of the first national music educators' conference. Durban: University of Natal.

Regelski, T.A. 1981. Teaching general music action learning for middle and secondary schools. New York: Schirmer Books.

Regelski, T.A. 1983a. Action learning versus the pied piper approach. Music Educators Journal, 69(8):55-57, 64, Apr. 
Regelski, T.A. 1983b. Action learning. Music Educators Journal, 69(6):46-50. Feb.

Regelski, T.A. 1986. Concept learning and action learning in music education. British Journal Of Music Education, 3(2):185-216.

Revans, R.W. 1980. Action learning: new techniques for management. London: Blond \& Briggs.

Revans, R.W. 1984. Action learning - are we getting there? Management Decision, 22(1): 45-52.

Robinson, K.M. 2006. White teacher, students of colour: Culturally responsive pedagogy for elementary general music in communities of colour. (In Frierson-Campbell, C. ed. 2006. Teaching music in the urban classroom: A guide to survival, success, and reform. Oxford: Rowman \& Littlefield Education. p. 35-53).

Schippers, H. \& Bartleet, B-L. 2013. The nine domains of community music: Exploring the crossroads of formal and informal music education. International Journal of Music Education, 31(4): 454-471.

Smit, E. \& Hauptfleisch, S. 1993. Effective music education in South Africa: Music education policy. Pretoria: Human Sciences Research Council.

Stanley, L.A., ed. 1992. Rap: the lyrics. New York: Penguin Books.

Van As, R. 2009. ' $n$ Interaktiewe benadering tot die integrering van musiek en wiskunde in die senior fase. Unpublished honnours dissertation. Potchefstroom: North-West University.

Van As, R. 2012. Die toepassing van die aksieleerbenadering in rap-onderrigleer. Unpublished master's short dissertation. Potchefstroom: North-West University. 